\title{
Through-Bond and Through-Space Interactions in [2,2]Cyclophanes
}

\author{
Sérgio E. Galembeck, ${ }^{\circledR * a}{ }^{*}$ Renato P. Orenha, ${ }^{\circledR b}$ Rafael M. Madeira, ${ }^{\oplus a}$ \\ Letícia B. Peixoto ${ }^{b}$ and Renato L. T. Parreira ${ }^{\circledR b}$ \\ ${ }^{a}$ Departamento de Química, Faculdade de Filosofia, Ciências e Letras de Ribeirão Preto, \\ Universidade de São Paulo, Av. Bandeirantes, 3900, Monte Alegre, 14040-901 Ribeirão Preto-SP, Brazil \\ ${ }^{b}$ Núcleo de Pesquisas em Ciências Exatas e Tecnológicas, Universidade de Franca (UNIFRAN), \\ Av. Dr. Armando Salles Oliveira, 201, Parque Universitário, 14404-600 Franca-SP, Brazil
}

\begin{abstract}
The interpretation of the distortions of the electron distribution in [2,2]cyclophanes (22-CPs) is controversial. Some studies indicate that there is an accumulation of electron density $(\rho)$ outside the cavity of 22-CPs. The nature of through-space (ts) interaction is still under debate. The relative importance of ts and through-bond (tb) is an open question. In an attempt to clarify these points, we have investigated five 22-CPs and their corresponding toluene dimers by molecular orbitals analysis, electron density difference analysis, some topological analysis of $\rho$ (quantum theory of atoms in molecules (QTAIM), electron localization function (ELF) and noncovalent interactions (NCI)), and energy decomposition analysis with natural orbitals for chemical valence (EDA-NOCV). $\rho$ is concentrated inside the inter-ring region. All the analyses indicated that ts is predominant. The ts is composed by attractive dispersion and Pauli repulsion, with a small covalent contribution. Except for $\mathbf{1}$ and $\mathbf{6}$, all the compounds present inter-ring bond paths.
\end{abstract}

Keywords: [2,2]cyclophanes, through bond interaction, through space interaction, non-covalent interaction, interacting quantum atoms (IQA)

\section{Introduction}

Cyclophanes are compounds that bear one or more aromatic rings, decks, connected by aliphatic chains, bridges. In some [2,2]cyclophanes, as [2,2]paracyclophane, (1), the inter-ring distance is shorter than twice the carbon van der Waals radius. Despite several studies ${ }^{1-25}$ on the electronic structure of [2,2]cyclophanes, mainly $\mathbf{1}$, certain points still are not totally understood, some related to the transannular interactions, or the interaction between aromatic rings, $\pi-\pi$ interaction, or stacking. First, the electron density $(\rho)$ distribution inside or outside the inter-ring region, or cavity. Some authors ${ }^{4-10}$ observed a concentration of $\rho$ outside the cavity, the "toothpaste-tube effect". Others ${ }^{1-3,11}$ do not observe this effect. The use of photoelectron spectroscopy for [2,2]paracyclophanes with an increasing number of bridges (2PCPs) indicated that the electron density is not concentrated outside the inter-ring region..$^{1,2}$ A theoretical study of the interaction of $\mathrm{Ru}\left[\left(\mathrm{NH}_{3}\right)_{3}\right]^{2+}$ with $2 \mathrm{PCPs}$ reached the same conclusion. ${ }^{3}$ Changes in the inter-ring distances reinforced the conclusions of both studies. On the other

*e-mail: segalemb@usp.br hand, theoretical and experimental studies ${ }^{4-10}$ showed that $\rho$ is concentrated in the outer faces of the rings. A study ${ }^{4}$ indicates that $\mathbf{1}$ is more reactive toward $\left[\mathrm{Cr}(\mathrm{CO})_{6}\right]$ than $p$-xylene due to repulsion between the rings, which increases $\rho$ outside the cavity. A computational study of bis $(2 \mathrm{CP}) \mathrm{Mn}^{2+}$ indicated that $\rho$ migrates from the external face of the rings towards the metal. This transannular effect is a consequence of the $\pi-\pi$ repulsion between the decks. ${ }^{5}$ A theoretical study of the interaction of 1 with cations came to the same conclusion, ${ }^{6}$ and so did some X-ray and theoretical analyses of $\mathbf{1}$ by quantum theory of atoms in molecules (QTAIM), which demonstrated $\rho$ deformation and an absence of charge concentration between the stacks, ${ }^{7-9}$ which is a prerequisite of transannular effects. ${ }^{7}$ In the $\eta^{6}$ complex of $\mathrm{Cr}(\mathrm{Co})_{3}$ with $(2)_{3}[1,3,5]$ cyclophane, $\rho$ flows to the metal, which diminishes the transannular repulsion..$^{10}$ In contrast to most studies, a work ${ }^{11}$ based on QTAIM concluded that charge is concentrated at the center of $\mathbf{1}$ and is delocalized between stacks. In a previous paper, ${ }^{12}$ we used natural bond orbitals (NBO), QTAIM, and the analysis of occupied molecular orbitals and found that only syn[2,2]metacyclophane, (2), and anti[2,2]metacyclophane, (3), present through space (ts) interaction. 
Other questions regard the ts interaction nature and origin. This kind of interaction was experimentally observed by cyclic voltammetry of $\mathbf{1}, \mathbf{2}$, and [2,2] orthocyclophane, (5). The changes in the oxidation potential were explained in terms of increasing ts interaction on going from 5 to 1. ${ }^{13}$ ts charge transfer was observed by comparing the hyperpolarizability of a derivative of $\mathbf{1}$ and its monomers. ${ }^{14,15}$ The HOMO (highest occupied molecular orbital) and LUMO (lowest unoccupied molecular orbital) of $\mathbf{1}$ are antibonding and bonding, respectively, in the inter-ring region. HOMOLUMO double excitations are important and reduce steric repulsion. Grimme ${ }^{16,17}$ called the interaction between stacks of $\mathbf{1}$ as "overlap-dispersive", which nowadays is known as a medium-range correlation, in order to distinguish it from the common van der Waals interaction. As mentioned in the previous paragraph, some experimental and computational papers indicated that the ts interaction is repulsive. ${ }^{4-6}$ The use of a molecular fragmentation method for a series of cyclophanes showed that the intramolecular energy is repulsive, which explains the aromatic ring distortion. ${ }^{18}$ QTAIM, non-covalent interaction (NCI), and thermochemical analysis concluded that repulsions dominate over attractive interactions. ${ }^{19}$ Some other authors concluded that this interaction is not attractive. ${ }^{7,8}$ An energy decomposition analysis (EDA) of stacked benzene dimer indicated that dispersion is the dominant interaction, followed by repulsive Pauli, electrostatic, and a small component of orbital interaction. ${ }^{20}$ Together, dispersion and Pauli repulsion are known as exchange-repulsion. A symmetry-adapted perturbation theory (SAPT) EDA of several stacked face-face complexes between benzene and substituted benzene suggested that the most important attractive interaction is dispersion, and that the sum of dispersion, exchange and induction is almost constant. ${ }^{21}$ The attraction between aromatic rings is dominated by dispersion, but it also has the contribution of the electrostatic component. At short distances, exchange-repulsion is the most important component of the interaction energy. ${ }^{17} \mathrm{NCI}$ analysis indicated significant repulsion interactions between aromatic rings. The attractive ts interactions are mainly dispersions. ${ }^{22}$ In recent papers Karter-Fenk and Hebert ${ }^{23,24}$ concluded that the most important interactions for polycyclic aromatic dimers are London dispersion and Pauli repulsion, with some participation of charge penetration effects. Ehrenfest forces of 1, obtained by QTAIM, point toward the inter-ring region, which indicates a net attractive force. ${ }^{11}$

A final question is the role of through bond (tb) interaction and the relative importance of ts and tb interactions. The tb interaction is dominated by interaction of double occupied orbitals, which is destabilizing. The ts interaction largely predominates over tb in $\mathbf{1} .{ }^{25}$ Some other experimental and theoretical works for this compound revealed that the role of tb is negligible or absent. ${ }^{5,7}$ In contrast, NBO for $\mathbf{1 , 2 , 3}$, and [2,2]metaparacyclophane, (4), showed that tb is more stabilizing than ts. ${ }^{12}$

In this work, we continue our studies of the electronic structure of $[2,2]$ cyclophanes. In our first paper ${ }^{26}$ on this subject, we investigated the conformations, strain energies, aromaticity, and chemical shifts of $\mathbf{1 , 2 , 3}$, and 4 . In a second work, ${ }^{12}$ we analyzed the ts and tb interactions by NBO, natural steric analysis (NSA), natural resonance theory (NRT), QTAIM, and frontier molecular orbitals. Other papers examined the electronic structure and aromaticity of compounds 1-3 perfluorinated in one ring ${ }^{27}$ and the effect of exohedric complexation of $\left[\mathrm{Ru}(\mathrm{NH})_{3}\right]^{2+}$ in $\mathbf{1}$ and some derivatives. ${ }^{3,28}$

Here, we analyze the electronic structures of 1-4 and 5, in a closed conformation (Scheme 1) by frontier molecular orbitals (FMO), Hirshfeld partition of electron density for the rings and the bridges ${ }^{29}$ QTAIM,${ }^{30}$ interacting quantum atoms (IQA), ${ }^{31}$ electron localization function (ELF), ${ }^{32}$ noncovalent interactions (NCI), ${ }^{33}$ and energy decomposition analysis along with the natural orbitals for chemical valence (EDA-NOCV) ${ }^{34,35}$ methods. We also study the toluene dimers 6-10 (Scheme 2), with the rings in the same position as in 1-5, as models of cyclophanes without bridges. We aim to understand the roles of the tb and ts interactions in [2,2]cyclophanes and the electron density distribution in the inter- and outer ring regions by using the most adequate electron density methods.
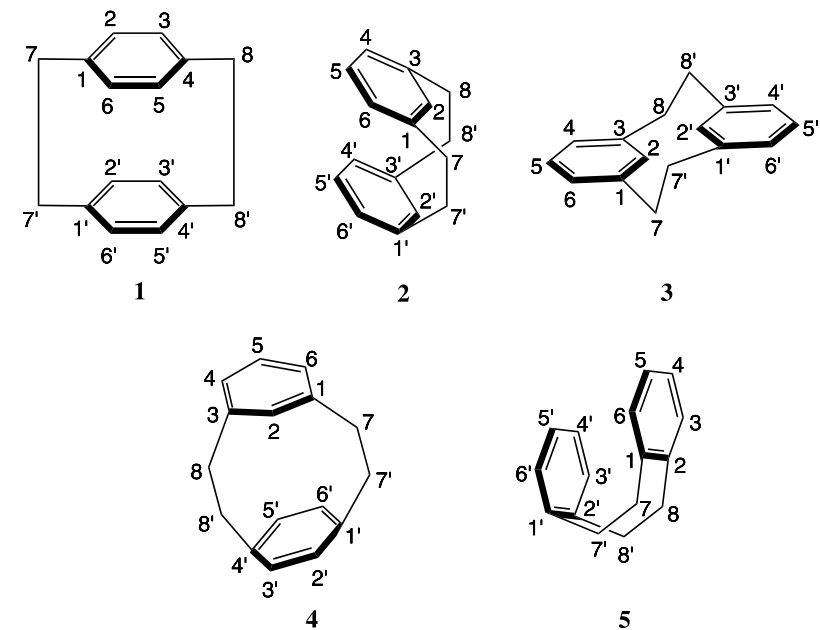

Scheme 1. [2,2]Cyclophanes.

\section{Methodology}

The compounds had their geometry optimized, and the vibrational frequencies were calculated by the PW6B95 $5^{36}$ D3(BJ) ${ }^{37} /$ def2-TZVP ${ }^{38}$ computational model; the Orca 4.04 

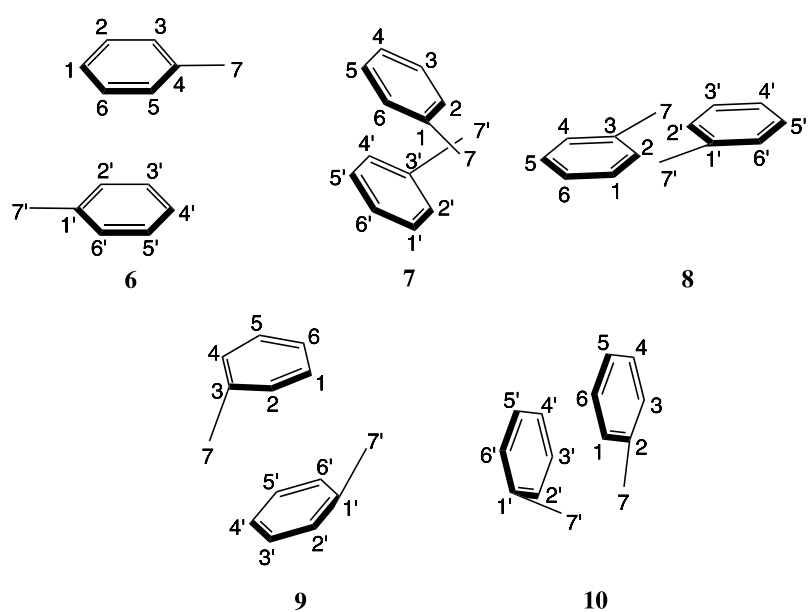

Scheme 2. Toluene dimers.

software was used. ${ }^{39}$ The IQA analyses were performed with AIMAll 19.02.13. ${ }^{40}$ The ELF and NCI analyses and Hirshfeld partition of electron density were conducted with Multiwfn 3.6. ${ }^{41}$ For the EDA-NOCV calculations, the geometries of all the studied compounds were optimized without restraints, and the vibrational frequencies were calculated from the BLYP $^{42}$-D3(BJ) ${ }^{37}$ method and TZ2P $^{43}$ basis set. The EDA-NOCV calculations were accomplished with the ADF2013 software. ${ }^{44}$

In the EDA method, the overall bond energy $\Delta \mathrm{E}$ between, for example, the $\mathrm{CH}_{3}-\mathrm{C}_{6} \mathrm{H}_{5}$ fragments is constructed from two main terms: $\Delta \mathrm{E}=\Delta \mathrm{E}_{\text {prep }}+\Delta \mathrm{E}_{\text {int }}{ }^{34}$ The $\Delta \mathrm{E}_{\text {prep }}$ comprises the amount of energy necessary to change the interacting fragments from their isolated structures and electronic states to the geometries and electronic states that they acquire when are interacting each other. The calculation of the $\Delta \mathrm{E}_{\text {prep }}$ term requires that the geometry of the isolated fragments and complexes need to be optimized again. The interaction energy $\Delta \mathrm{E}_{\text {int }}$ match up to the actual energy change when the geometrically deformed $\mathrm{CH}_{3}-\mathrm{C}_{6} \mathrm{H}_{5}$ fragments are joined to form the complete complex. The last energetic component $\Delta \mathrm{E}_{\text {int }}$ also can be decomposed into electrostatic, Pauli repulsion, orbital interactions, and dispersion components: $\Delta \mathrm{E}_{\text {int }}=\Delta \mathrm{V}_{\text {elstat }}+\Delta \mathrm{E}_{\text {Pauli }}+\Delta \mathrm{E}_{\text {oi }}+\Delta \mathrm{E}_{\text {disp. }}$. The term $\Delta \mathrm{V}_{\text {elstat }}$ represents the quasi-classical electrostatic interaction between unperturbed charge densities and nuclei of the geometrically deformed fragments. The Pauli repulsion $\Delta \mathrm{E}_{\text {Pauli }}$ contains the destabilizing interactions between the occupied orbitals and is accountable for the steric repulsion. The orbital interactions $\Delta \mathrm{E}_{\mathrm{oi}}$ reflects the charge transfer (donor-acceptor interactions between occupied orbitals on one fragment with the empty orbitals of another fragment) and polarization (unoccupied/occupied orbital mixing in one moiety due the presence of another moiety). The term $\Delta \mathrm{E}_{\text {disp }}$ accounts for dispersion contributions.

\section{Results and Discussion}

Over the last years, the geometry of $\mathbf{1}$ has been studied by experimental ${ }^{9,45,46}$ and theoretical methods. ${ }^{16,17,26,37}$ The experimental studies have focused on the low-temperature phase transition between the $\mathrm{D}_{2 \mathrm{~h}}$ and $\mathrm{D}_{2}$ structures, which is driven by the twist of the ethylene bridges, ${ }^{45,46}$ and on the electron density of $1 .^{9}$ The theoretical studies have consisted mainly of benchmark computational methods. ${ }^{16,17,26,37}$ In our first study about cyclophanes, we concluded that B3LYP/6-31+G(d,p), B3PW91/6-31+G(d,p), and MP2/6-31+G(d,p) are the best computational models for bond lengths. ${ }^{26}$ Bachrach $^{47}$ concluded that M06-2X and B97X-D are the best methods to describe 1. Grimme ${ }^{16}$ observed that SCS-MP2/TZV(2df,2p) accurately predicts all the geometrical parameters of $\mathbf{1}$ including the interring distance, which is not adequately calculated by MP2 or density functional theory (DFT) methods. This author ${ }^{17,37}$ developed some dispersion corrections for DFT methods and tested D3 and D3(BJ) for several cyclophanes, including $\mathbf{1}$ and $\mathbf{2}$, and concluded that PW6B95-D3(BJ) and TPSS-D3(BJ) are the best methods for the geometries and electronic structure. Additionally, only the experimental molecular structure of $\mathbf{4}$ is found in the literature. ${ }^{48}$ The structural parameters of $\mathbf{1}$ and $\mathbf{4}$ obtained by PW6B95-D3(BJ)/def2-TZVP herein agree very well with previous experimental ${ }^{9,45,46}$ and theoretical ${ }^{16,17,37,38}$ studies, as observed by the absolute deviation from experimental values (see Tables S1 and S4, Supplementary Information (SI) section). Here, we compare the mean and maximum deviations of bond lengths and bond angles for 1 and 4 from PW6B95-D3(BJ)/def2-TZVP, (A), of this work, B3PW91/6-31G+(d,p), (B), from our first paper on cyclophanes, ${ }^{26}$ and SCS-MP2/TZV(2df,2p), (C). ${ }^{16}$ For $\mathbf{1}$, we concluded that for bond lengths the best method is $\mathrm{C}$, and B is slightly better than A (Tables S1, S4 and S6). The most accurate methods for inter-ring distance for $\mathbf{1}$ were $\mathrm{A}$ and $\mathrm{C}$, with $\mathrm{B}$ presenting larger deviations. In contrast, the bond angles are best described for A than for B. Bond lengths for $\mathbf{4}$ are well described for methods A and B, and bond angles are better described for $\mathrm{A}$. The most accurate method for the $\mathrm{C} 1-\mathrm{C} 7-\mathrm{C} 7{ }^{\prime}-\mathrm{C} 1^{\prime}$ dihedral angle for $\mathbf{1}$ is $\mathrm{A}$. We can conclude that benchmark studies for the geometries of $[2,2]$ cyclophanes are necessary. We obtained the toluene dimers 6-10 from the respective cyclophanes by deleting one methylene group from each bridge and by completing the valence of the phenyl and methyl groups, without any optimization. We studied toluene dimers instead of $p$-xylene dimers to avoid steric clashes between methyl groups.

For all the studied [2,2]cyclophanes, HOMO is antibonding in the inter-ring region. The exception is $\mathbf{4}$, in 
which HOMO is concentrated in one ring. In the case of 1 and 3-5, LUMO is bonding in this region. As for $\mathbf{2}$, this behavior is observed for LUMO+1. Figure S1 (SI section) shows some examples of these orbitals. Because Grimme ${ }^{16}$ verified that the electron correlation between HOMO and LUMO of 1 plays a significant role in the inter-ring interaction, we investigated whether the HOMO-LUMO energy difference is related to the inter-ring distances or the minimum distance between carbons (Table S7, SI section). The inter-ring distances are determined by the distance between the center of the stacks. Changes in the HOMO and LUMO energies or in the HOMO-LUMO energy differences do not correlate with these distances. The same observations made for $\mathbf{1 - 5}$ can be made for the dimers 6-10. The HOMO and LUMO energies of 6-10 increase and decrease, respectively, as compared to the studied [2,2]cyclophanes, except for $\mathbf{1}$. These results can be understood by considering the four-electron destabilization between the aliphatic bridge and the aromatic ring. ${ }^{25}$

We also analyzed the Hirshfeld contributions of the electron density for the fragments, aromatic ring, $\mathrm{C}_{6} \mathrm{H}_{4}$, and aliphatic bridge, $\mathrm{C}_{2} \mathrm{H}_{4} \cdot{ }^{29}$ For 1-5, the stacks present the largest contribution to the frontier molecular orbitals HOMO-4 to LUMO+4. Tables 1 and S8-S11 (SI section) list the data for $\mathbf{1}$ and for $\mathbf{2 - 5}$, respectively, which suggest that the contribution from tb is less important than the contribution from ts. ${ }^{4,6}$ The contribution from the bridges prevail below HOMO-5 and above LUMO+5.

To verify if $\rho$ is concentrated inside or outside the interring region of the cyclophanes, the electron density difference between toluene dimers, 6-10, and its monomers was analyzed (Figures 1 and S2, SI section). All maps indicate that the electron density migrates inside the inter-ring region, from the center of the cavity to the neighborhood of ring carbons. There is a small contribution from the outside part of the cavity. This indicates that the "toothpaste-tube effect" is not present in the studied systems.

For all the studied systems, lines of constant $\rho$ can be observed between the stacks, indicating a transannular interaction, which is in line with the computational and experimental observations discussed in previous paragraphs (Figures 2 and S3, SI section). In the inter-ring region, it is possible to notice the lack of VSCC (valence shell charge concentration), in contrast to that observed for $\mathrm{C}-\mathrm{C}$ bonds. So, the valence shell inside the cavity is VSCD (valence shell charge depletion). On the basis of QTAIM, a cyclophane and its equivalent dimer have similar $\rho$ topology, as in the case of $\mathbf{1}$ and $\mathbf{6}$, which reinforces that the ts interaction predominates in [2,2]cyclophanes.

We analyzed the nature of the interaction between carbons on different rings by delocalization indexes (DIs;
Table 1. Orbital energy $\left(\mathrm{E}_{\text {orb }}\right)$ and total Hirshfeld contributions for both the rings and the two bridges for $\mathbf{1}$

\begin{tabular}{|c|c|c|c|}
\hline & \multirow{2}{*}{$\mathrm{E}_{\text {orb }}{ }^{\mathrm{a}} / \mathrm{a} . \mathrm{u}}$. & \multicolumn{2}{|c|}{ Contribution / \% } \\
\hline & & Rings & Bridges \\
\hline HOMO-10 & -0.35430 & 86.35 & 14.31 \\
\hline HOMO-9 & -0.34780 & 64.58 & 35.19 \\
\hline HOMO-8 & -0.34600 & 56.17 & 43.55 \\
\hline HOMO-7 & -0.34340 & 20.10 & 80.56 \\
\hline HOMO-6 & -0.34100 & 94.66 & 5.43 \\
\hline HOMO-5 & -0.32020 & 71.84 & 28.16 \\
\hline HOMO-4 & -0.31450 & 74.18 & 25.92 \\
\hline HOMO-3 & -0.26550 & 98.76 & 1.20 \\
\hline HOMO-2 & -0.24390 & 75.75 & 24.36 \\
\hline HOMO-1 & -0.23460 & 99.13 & 0.89 \\
\hline HOMO & -0.22650 & 90.85 & 9.08 \\
\hline LUMO & -0.02940 & 93.02 & 7.01 \\
\hline LUMO+1 & -0.01400 & 82.34 & 17.91 \\
\hline LUMO+2 & -0.00010 & 84.10 & 15.81 \\
\hline LUMO+3 & 0.00690 & 97.22 & 2.77 \\
\hline LUMO+4 & 0.03970 & 69.29 & 30.22 \\
\hline LUMO+5 & 0.05690 & 32.58 & 67.49 \\
\hline LUMO+6 & 0.06120 & 67.03 & 32.28 \\
\hline LUMO+7 & 0.07670 & 38.78 & 61.03 \\
\hline LUMO+8 & 0.07910 & 41.85 & 58.45 \\
\hline LUMO+9 & 0.08190 & 61.13 & 41.93 \\
\hline
\end{tabular}

${ }^{a}$ These energies are calculated by Multiwfn software ${ }^{41}$ and therefore are different from those calculated from Orca 4.04, ${ }^{39}$ presented in Table S6 (SI section). HOMO: highest occupied molecular orbital; LUMO: lowest unoccupied molecular orbital.

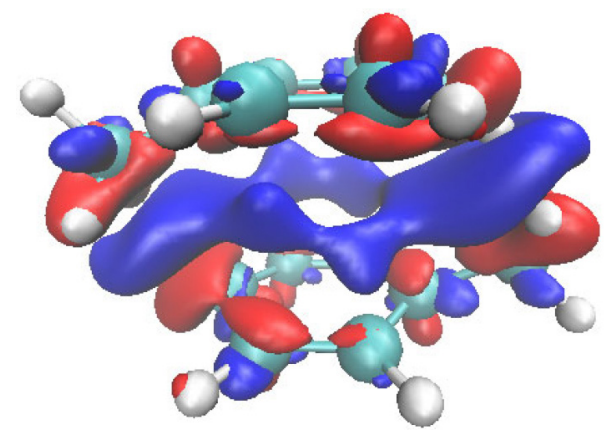

Figure 1. Electron density difference map of 1. Red: $\rho=0.001$, blue: $\rho=-0.001$.

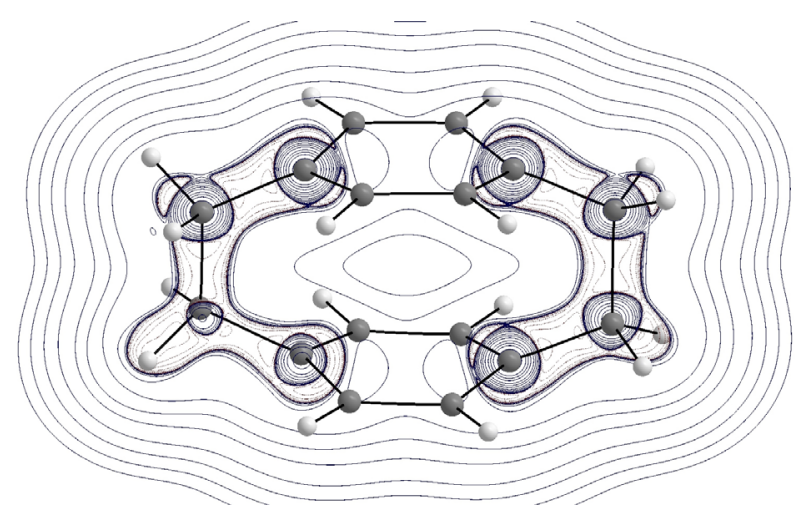

Figure 2. Contour map of the Laplacian of the electron density, $\nabla^{2} \rho$, for $\mathbf{1}$. The continuous lines represent positive, and the thinnest dotted line negative $\nabla^{2} \rho$. 
$\delta(\mathrm{A}, \mathrm{B}))$ and IQA parameters (Tables 2 and S12, SI section). DIs and energy components obtained by IQA indicate that there are no changes between a [2,2]cyclophane and its equivalent dimer. Once again, this reinforces the small participation of the bridges in the interaction between the rings. The DIs of carbons in different rings are two orders of magnitude smaller than the DIs of carbons in covalent bonds and of the same order of magnitude of weak $\mathrm{C} 1-\mathrm{C} 7$ ' interaction. All these interactions are stabilizing because the total interaction energy $\left(\mathrm{E}_{\text {int }}{ }^{\mathrm{AB}}\right)$ is negative and small, suggesting that the nature of these interactions are of van der Waals type. ${ }^{29}$ The exchange-correlation component $\left(\mathrm{E}_{\mathrm{xc}}{ }^{\mathrm{AB}}\right)$ is several times larger than the classic one $\left(\mathrm{E}_{\mathrm{cl}}{ }^{\mathrm{AB}}\right)$. The former is stabilizing, and the latter is positive, which indicates some covalent character for these inter-ring $\mathrm{C}$---C interactions. ${ }^{30}$ This indication of $\mathrm{C}---\mathrm{C}$ covalent character must be viewed with reservation, because there are few

Table 2. Delocalization indexes, $\delta(\mathrm{A}, \mathrm{B})$, and energetic components of IQA, $\mathrm{E}_{\mathrm{int}}{ }^{\mathrm{AB}}, \mathrm{E}_{\mathrm{xc}}{ }^{\mathrm{AB}}$, and $\mathrm{E}_{\mathrm{cl}}{ }^{\mathrm{AB}}$, for [2,2]cyclophanes 1-5 ${ }^{\mathrm{a}}$

\begin{tabular}{|c|c|c|c|c|c|}
\hline & Atoms & $\begin{array}{c}\delta(\mathrm{A}, \mathrm{B}) / \\
\text { a.u. }\end{array}$ & $\begin{array}{c}\mathrm{E}_{\text {int }}^{\mathrm{AB} /} \\
\text { a.u. }\end{array}$ & $\begin{array}{c}\mathrm{E}_{\mathrm{cl}}^{\mathrm{AB}} / \\
\text { a.u. } \\
\end{array}$ & $\begin{array}{c}\mathrm{E}_{\mathrm{xc}}^{\mathrm{AB}} / \\
\text { a.u. }\end{array}$ \\
\hline \multirow{6}{*}{1} & $\mathrm{C} 1-\mathrm{C} 1{ }^{\prime}$ & 0.033 & -0.0053 & 0.0009 & -0.0062 \\
\hline & $\mathrm{C} 2-\mathrm{C} 2$ ' & 0.029 & -0.0038 & 0.0015 & -0.0053 \\
\hline & $\mathrm{C} 1-\mathrm{C} 2^{\mathrm{b}}$ & 1.340 & -0.3651 & 0.0429 & -0.4079 \\
\hline & $\mathrm{C} 1-\mathrm{C} 7^{\mathrm{b}}$ & 1.008 & -0.2883 & 0.0229 & -0.3112 \\
\hline & $\mathrm{C} 1-\mathrm{C} 7^{\circ}$ & 0.045 & -0.0062 & 0.0007 & -0.0069 \\
\hline & C7-C7' & 0.926 & -0.2574 & 0.0144 & -0.2717 \\
\hline \multirow{3}{*}{2} & $\mathrm{C} 1-\mathrm{C} 1{ }^{\prime}$ & 0.030 & -0.0043 & 0.0009 & -0.0052 \\
\hline & $\mathrm{C} 2-\mathrm{C} 2$ ' & 0.060 & -0.0110 & 0.0017 & -0.0127 \\
\hline & C4-C4' & 0.012 & -0.0006 & 0.0011 & -0.0017 \\
\hline \multirow{2}{*}{3} & $\mathrm{C} 1-\mathrm{C} 1{ }^{\prime}$ & 0.016 & -0.0021 & 0.0002 & -0.0023 \\
\hline & $\mathrm{C} 2-\mathrm{C} 2$ ' & 0.074 & -0.0142 & 0.0015 & -0.0157 \\
\hline \multirow{4}{*}{4} & $\mathrm{C} 1-\mathrm{C} 1{ }^{\prime}$ & 0.031 & -0.0053 & 0.0006 & -0.0059 \\
\hline & $\mathrm{C} 2-\mathrm{C} 2$ ' & 0.024 & -0.0037 & 0.0003 & -0.0040 \\
\hline & C3-C3' & 0.009 & -0.0011 & -0.0002 & -0.0010 \\
\hline & $\mathrm{C} 4-\mathrm{C} 5$, & 0.021 & -0.0026 & 0.0009 & -0.0034 \\
\hline \multirow{3}{*}{5} & $\mathrm{C} 1-\mathrm{C} 1{ }^{\prime}$ & 0.029 & -0.0041 & 0.0012 & -0.0053 \\
\hline & $\mathrm{H}^{\prime}(\mathrm{C} 7)-\mathrm{H}^{\prime}\left(\mathrm{C} 8^{\prime}\right)^{\mathrm{c}}$ & 0.019 & -0.0038 & 0.0002 & -0.0039 \\
\hline & $\mathrm{H}^{\prime}(\mathrm{C} 7)-\mathrm{H}^{\prime}(\mathrm{C} 8)^{\mathrm{c}}$ & 0.011 & -0.0018 & 0.0001 & -0.0019 \\
\hline
\end{tabular}

${ }^{\mathrm{a}}$ Only values of $\delta(\mathrm{A}, \mathrm{B})>0.001$ are presented; ${ }^{\mathrm{b}}$ these data are similar for all other compounds; ' $\mathrm{H}$ ' are the hydrogens situated inside the ring. IQA: interacting quantum atoms; $\mathrm{E}_{\text {int }}{ }^{\mathrm{AB}}$ : IQA total interaction energy; $\mathrm{E}_{\mathrm{xc}}{ }^{\mathrm{AB}}$ : IQA exchange-correlation energy component; $\mathrm{E}_{\mathrm{cl}}{ }^{\mathrm{AB}}$ : IQA classic energy component. works that classify chemical bonds using IQA. Atoms involved in these interactions have a closed shell, and their covalent character is very small or absent, as indicated by QTAIM (next paragraph). The stabilizing nature of these interactions indicate that the inter-ring peripherical interaction is attractive, but the inner interaction between stacks is repulsive, as the common interpretation for the boat conformation of the rings in $\mathbf{1},{ }^{18,19}$ and by the fact that the stacked conformation of benzene dimer is a transition state. $^{49}$

Except for $\mathbf{1}$ and $\mathbf{6}$, the molecular graph of the studied systems present a bond path (BP) and a bond critical point (BCP) between the rings, as noticed in our previous work ${ }^{12}$ (Figure S4, SI section, and Table 3). The absence of a BCP in these systems could indicate a nonexistence of attractive interactions, as some authors interpret the absence of an inter-ring BCP in $\mathbf{1}$ as an indication of a lack of interaction between the rings. ${ }^{79}$ Other researchers found evidences that a BP is the preferred exchange-correlation path. ${ }^{50} \mathbf{2}$ and $\mathbf{3}$ display an inter-ring BCP between $\mathrm{C} 2---\mathrm{C} 2$ '. In both cases, $\mathrm{E}_{\mathrm{XC}}{ }^{\text {inter }}$ is much larger than for the other C---C' interaction, explaining the observation of this BP. For $\mathbf{4}$, determining $\mathrm{E}_{\mathrm{XC}}{ }^{\text {inter }}$ is difficult because the BP links two critical points. This indicates a conflict structure, which can be seen by the high ellipticity, $\varepsilon_{\mathrm{b}}(\mathrm{r}) .5$ presents a curved BP connecting two bridge hydrogens, $\mathrm{H}(\mathrm{C} 7)-\mathrm{H}\left(\mathrm{C} 8^{\prime}\right)$. This curved BP points to a topologically unstable structure. By comparing $\mathrm{E}_{\mathrm{XC}}{ }^{\text {inter }}\left[\mathrm{H}(\mathrm{C} 7)-\mathrm{H}\left(\mathrm{C} 8^{\prime}\right)\right]$ with $\mathrm{E}_{\mathrm{XC}}{ }^{\text {inter }}[\mathrm{H}(\mathrm{C} 7)-\mathrm{H}(\mathrm{C} 8)]$, the former presents a larger value despite the shorter distance of the latter, reinforcing the relation between $\mathrm{BP}$ and $\mathrm{E}_{\mathrm{XC}}$ inter. As in the case of C---C inter-ring interactions, these $\mathrm{H}---\mathrm{H}$ interactions can be classified as van der Waals interactions with some covalent character.

On the basis of the small $\rho_{b}(r)$ (electron density in the $\mathrm{BCP}$ ) values, small and positive Laplacian of electron density $\left(\nabla^{2} \rho_{b}(r)\right)$ and total energy density $\left(H_{b}(r)\right)$ at the C---C inter stack $\mathrm{BCP}$, we concluded that these interactions have a closed shell nature. ${ }^{12}$ Because $\delta(\mathrm{C}---\mathrm{C})$ is very small, the potential energy density, $\left(\mathrm{V}_{\mathrm{b}}(\mathrm{r})\right)$ is negative, and the kinetic energy density $\left(\mathrm{G}_{\mathrm{b}}(\mathrm{r})\right)$ is ca. $\left|\mathrm{V}_{\mathrm{b}}(\mathrm{r})\right|$, so these interactions could be classified as van der Waals (Table 3). ${ }^{51}$ When $-\mathrm{G}_{\mathrm{b}}(\mathrm{r}) / \mathrm{V}_{\mathrm{b}}(\mathrm{r})$ is larger than one, these interactions are noncovalent..$^{52}$

Table 3. QTAIM parameters for the inter-ring BCP of 2-5

\begin{tabular}{lcccccccc}
\hline & $\mathrm{BCP}$ & $\rho_{\mathrm{b}}(\mathrm{r})$ & $\nabla^{2} \rho_{\mathrm{b}}(\mathrm{r}) /$ a.u. & $\varepsilon_{\mathrm{b}}(\mathrm{r}) /$ a.u. & $\mathrm{V}_{\mathrm{b}}(\mathrm{r}) /$ a.u. & $\mathrm{G}_{\mathrm{b}}(\mathrm{r}) /$ a.u. & $\mathrm{H}_{\mathrm{b}}(\mathrm{r}) /$ a.u. & $-\mathrm{G}_{\mathrm{b}}(\mathrm{r}) / \mathrm{V}_{\mathrm{b}}(\mathrm{r}) /$ a.u. \\
\hline $\mathbf{2}$ & C2--C2 & 0.020 & 0.059 & 0.207 & -0.013 & 0.014 & 0.001 & 1.069 \\
$\mathbf{3}$ & $\mathrm{C} 2--\mathrm{C} 2$ & 0.022 & 0.064 & 0.164 & -0.014 & 0.015 & 0.001 & 1.058 \\
$\mathbf{5}$ & C2--C2 & 0.012 & 0.038 & 1.472 & -0.007 & 0.009 & 0.001 & 1.143 \\
\hline
\end{tabular}

BCP: bond critical point; $\rho_{b}(r)$ : electron density in the BCP; $\nabla^{2} \rho_{b}(r)$ : Laplacian of $\rho_{b}(r) ; \varepsilon_{b}(r)$ : ellipticity in the BCP; $V_{b}(r)$ : potential energy density in the BCP; $\mathrm{G}_{b}(\mathrm{r})$ : kinetic energy density in the BCP; $\mathrm{H}_{b}(\mathrm{r})$ : total energy density in the BCP. 
According to IQA and QTAIM, the ts interaction is of van der Waals type, with no or a small covalent character. This agrees with the analysis made by Grimme. ${ }^{16,17}$

For all the studied systems, ELF indicates that there are no dysinaptic basins between carbons in different rings (Figure 3). Because the core basins, $\mathrm{C}(\mathrm{C})$, of the ring carbons are not deformed, and the merge of $\mathrm{C}(\mathrm{C})$ situated in different stacks is $\eta<0.1$ ( $\eta$ : ELF), interaction between the rings is of van der Waals type. ${ }^{53}$ All the systems present aromatic dysinaptic basins $(\mathrm{V}(\mathrm{C}, \mathrm{C}))$ with small variations in the populations, suggesting a relatively high aromaticity, as observed in our first work on cyclophanes (Figure $3 b$ ). ${ }^{26}$

$\mathrm{NCI}$ indicates the presence of repulsive and attractive inter-ring interactions (Figures 4 and S5, SI section). Apart from the strong repulsions in the center of aromatic systems, the studied [2,2]cyclophanes and corresponding (a)

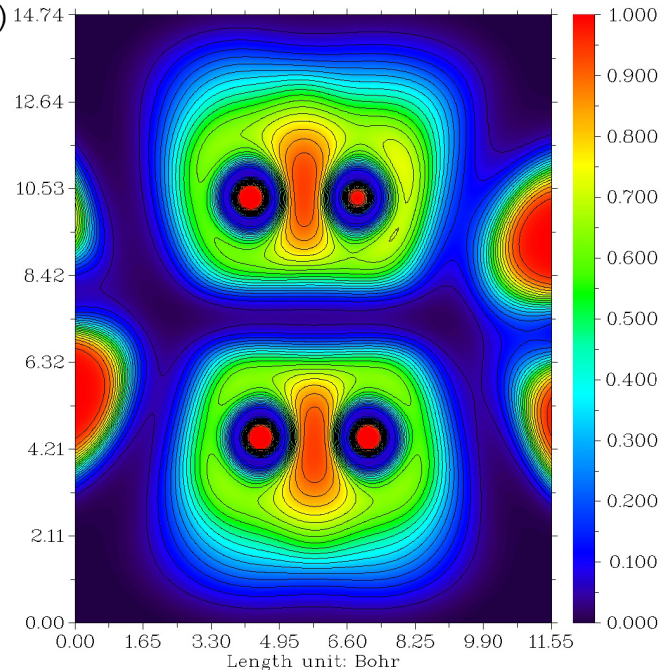

(b)

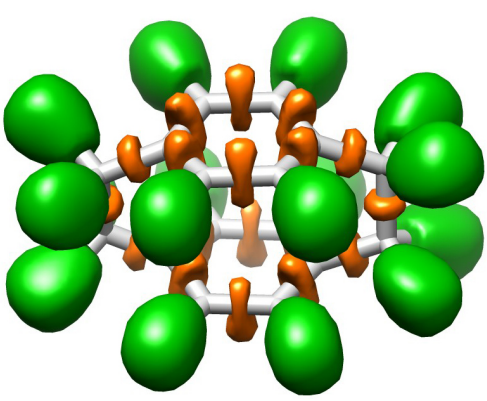

Figure 3. (a) Color-codified map containing the contour lines of the ELF for the $\mathrm{C}(2)-\mathrm{C}(3)---\mathrm{C}\left(3^{\prime}\right)-\mathrm{C}\left(2^{\prime}\right)$ region of $\mathbf{1}$; (b) ELF isosurface ( $\left.\eta=0.8\right)$ in $\mathbf{1}$.

(a)

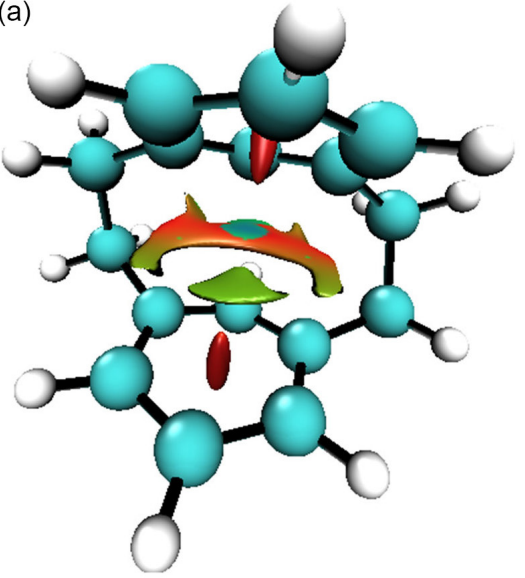

(c)

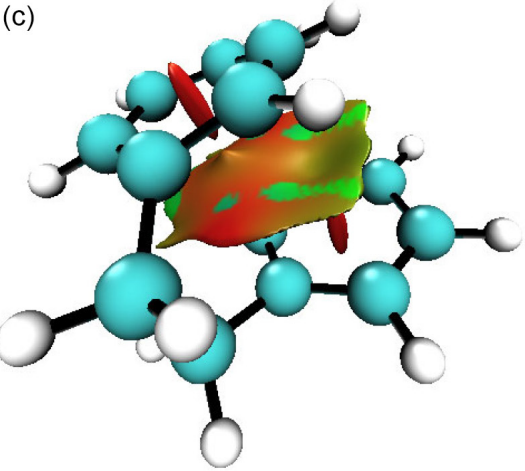

(b)

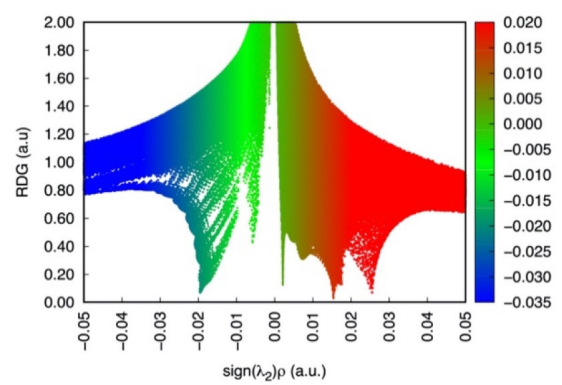

(d)

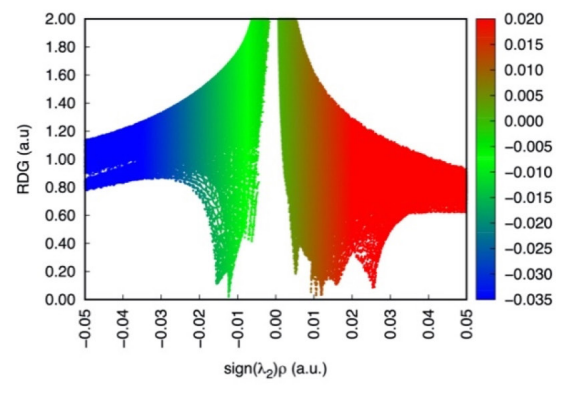

Figure 4. (a) NCI surface and (b) NCI plot for 2; (c) NCI surface and (d) NCI plot for 4. 
dimers could be classified into two different classes, according to the behavior of the NCI plots. 1, 2, and $\mathbf{3}$ exhibit inter-ring repulsions with sign $\left|\lambda_{2}\right| \rho\left(\lambda_{2}\right.$ : second eigenvalue of the Hessian of $\rho$ ) ca. 0.015 , and medium to strong attractions with sign $\left|\lambda_{2}\right| \rho \leq-0.02$. These attractions are in the limit between van der Waals and stronger closed shell interactions, like hydrogen bonds. 4 and 5 have less intense repulsions and van der Waals attractions. The stronger attractions in the NCI plots of $\mathbf{2}$ and $\mathbf{3}$ are related to the inter-ring BP, which is not observed for the weaker and topologically unstable BPs in $\mathbf{4}$ and $\mathbf{5}$. This is in line with the observations made by Majerz and Dziembowka ${ }^{22}$ for whom $\rho_{b}(r) \geq 0.013$ indicates $\pi-\pi *$ interactions between different rings. The $\rho_{b}(r)$ values of $\mathbf{2}$ and $\mathbf{3}$ are higher than the proposed cutoff (Table 3). On the other hand, 4 and $\mathbf{5}$ have lower $\rho_{b}(r)$ than the limit. However, the conclusion that $\rho_{\mathrm{b}}(\mathrm{r})$ lower than the proposed value can be related to very weak interactions needs to be further explored because IQA indicates that all the C--C' interactions, $\mathrm{C}$ and $\mathrm{C}^{\prime}$ in different rings, present significant interactions, of the same nature (Table 2). Analyzing the NCI surfaces, we notice that 1 present strong $\mathrm{C}---\mathrm{C}$ attractions, the $\mathrm{C}---\mathrm{C}$ attractions of $\mathbf{2}, \mathbf{3}$ and $\mathbf{4}$ are smaller, and 5 has some $\mathrm{H}---\mathrm{H}$ attractions. In all systems, interactions between bridgehead carbons are repulsive. Also, the repulsions were concentrated in the inter-ring inner part.

To explore the information about the tb and ts interactions in cyclophanes, we conducted EDA by considering the interactions between the ${ }^{\circ}\left(\mathrm{CH}_{2}\right)-\mathrm{C}_{6} \mathrm{H}_{4}-\left(\mathrm{CH}_{2}\right)$ structures in 1-5 (Scheme 1) and the interactions between the $\mathrm{CH}_{3}-\mathrm{C}_{6} \mathrm{H}_{5}$ molecules in 6-10 (Scheme 2). These interactions have attractive bond energy, $\Delta \mathrm{E}$, (Table 4 ) because the interaction energy $\left(\Delta \mathrm{E}_{\text {int }}\right)$ between the fragments is more favorable than the preparation energy $\left(\Delta \mathrm{E}_{\text {prep }}\right)$. For $\mathbf{1 - 5}$, the orbital interaction energy $\left(\Delta \mathrm{E}_{\mathrm{oi}}\right)$ is the most important attractive energetic term of $\Delta \mathrm{E}_{\text {int }}$ (Table 4), showing that the interaction between the $\cdot\left(\mathrm{CH}_{2}\right)-\mathrm{C}_{6} \mathrm{H}_{4}-\left(\mathrm{CH}_{2}\right)$ fragments is predominantly covalent, which can be explained by the rupture of the $\mathrm{C}-\mathrm{C}$ covalent bonds in the bridges. These compounds are stabilized by $\Delta \mathrm{E}_{\mathrm{oi}}$ and the electrostatic energy $\left(\Delta \mathrm{V}_{\text {elstat }}\right)$ and destabilized by Pauli repulsion $\left(\Delta \mathrm{E}_{\text {Pauli }}\right)$. The contribution of the dispersion energy $\left(\Delta \mathrm{E}_{\text {disp }}\right)$ to the stabilization of $\mathbf{1 - 5}$ is negligible. In contrast, the dispersion energy $\left(\Delta \mathrm{E}_{\text {disp }}\right)$ is the most relevant attractive energetic term of $\Delta \mathrm{E}_{\text {int }}$ in 6-10, with significant contribution from $\Delta \mathrm{V}_{\text {elstat }}$ and $\Delta \mathrm{E}_{\mathrm{oi}}$. For 1-10, Pauli repulsion is quite large, which can be attributed to the four-electron interaction between the occupied orbitals of the aromatic rings. Given that 6-10 present ts interactions only, the most relevant contributions are attractive dispersion and Pauli repulsion, or van der Waals interaction. This in agreement with all the results presented in this work and with Grimme's analysis. ${ }^{16,17} \Delta \mathrm{E}_{\text {Pauli }}$ and $\Delta \mathrm{E}_{\text {disp }}$ almost cancel each other, and $\Delta \mathrm{V}_{\text {elstat }}$ and $\Delta \mathrm{E}_{\mathrm{oi}}$ stabilize these dimers. The last term could indicate a small covalent character.

The NOCV methodology was applied to shed light on the most significant covalent interactions. The NOCV method allows that the orbital interactions between the fragments, for example, $\mathrm{CH}_{3}-\mathrm{C}_{6} \mathrm{H}_{5}$ may be decomposed into pairwise contributions of the most relevant molecular orbitals. The pairwise orbital interaction of a specific bond can be visualized from the shape of the deformation density $\left(\Delta \rho_{k}(r)\right)$ where the red and blue regions indicate the electronic density outflow and inflow, respectively. It is important highlight that the NOCV method also allows quantify the energetic $\left(\Delta \mathrm{E}_{\mathrm{o}, \mathrm{k}}\right)$ contribution of each density deformation channel $\left(\Delta \rho_{\mathrm{k}}\right)$ to $\Delta \mathrm{E}_{\mathrm{oi} \cdot}{ }^{33}$ Figures 5 and S6 (SI

Table 4. Analysis of the chemical bond by EDA-NOCV. The interactions between the $\left(\mathrm{CH}_{2}\right)-\mathrm{C}_{6} \mathrm{H}_{4}-\left(\mathrm{CH}_{2}\right)$ fragments were analyzed in 1-5. The interactions between the $\mathrm{CH}_{3}-\mathrm{C}_{6} \mathrm{H}_{5}$ fragments were analyzed in 6-10. Values in parentheses correspond to the percentage of each stabilizing contribution $\left(\Delta \mathrm{V}_{\text {elstat }}+\Delta \mathrm{E}_{\text {oi }}+\Delta \mathrm{E}_{\text {disp }}=100 \%\right)$

\begin{tabular}{lccccccccc}
\hline Compound & $\begin{array}{c}\Delta \mathrm{E} / \\
\left(\mathrm{kcal} \mathrm{mol}^{-1}\right)\end{array}$ & $\begin{array}{c}\Delta \mathrm{E}_{\mathrm{prep}} / \\
\left(\mathrm{kcal} \mathrm{mol}^{-1}\right)\end{array}$ & $\begin{array}{c}\Delta \mathrm{E}_{\text {int }} / \\
\left(\mathrm{kcal} \mathrm{mol}^{-1}\right)\end{array}$ & $\begin{array}{c}\Delta \mathrm{V}_{\text {elstat }} / \\
\left(\mathrm{kcal} \mathrm{mol}^{-1}\right)\end{array}$ & $\begin{array}{c}\Delta \mathrm{E}_{\text {Pauli }} / \\
\left(\mathrm{kcal} \mathrm{mol}^{-1}\right)\end{array}$ & $\begin{array}{c}\Delta \mathrm{E}_{\mathrm{oi}} / \\
\left(\mathrm{kcal} \mathrm{mol}^{-1}\right)\end{array}$ & $\begin{array}{c}\Delta \mathrm{E}_{\text {disp }} / \\
\left(\mathrm{kcal} \mathrm{mol}^{-1}\right)\end{array}$ & $\begin{array}{c}\Delta \mathrm{E}_{\mathrm{oi}, 1} / \\
\left(\mathrm{kcal} \mathrm{mol}^{-1}\right)\end{array}$ & $\begin{array}{c}\Delta \mathrm{E}_{\mathrm{oi}, 2} / \\
\left(\mathrm{kcal} \mathrm{mol}^{-1}\right)\end{array}$ \\
\hline $\mathbf{1}$ & -108.97 & 98.78 & -207.75 & $-260.81(25)$ & 823.26 & $-749.76(73)$ & $-20.44(2)$ & -362.35 & -214.54 \\
$\mathbf{2}$ & -95.80 & 109.64 & -205.44 & $-272.03(26)$ & 835.26 & $-750.65(72)$ & $-18.03(2)$ & -270.94 & -305.37 \\
$\mathbf{3}$ & -105.59 & 99.64 & -205.23 & $-284.50(27)$ & 864.75 & $-768.23(72)$ & $-17.23(2)$ & -270.96 & -313.37 \\
$\mathbf{4}$ & -108.33 & 101.78 & -210.11 & $-281.48(26)$ & 864.84 & $-773.30(72)$ & $-20.17(2)$ & -290.63 & -292.63 \\
$\mathbf{5}$ & -123.21 & 97.00 & -220.21 & $-288.35(25)$ & 921.77 & $-840.86(74)$ & $-12.77(1)$ & -353.23 & -292.34 \\
$\mathbf{6}$ & -4.92 & 0.34 & -5.26 & $-3.51(23)$ & 10.15 & $-1.78(12)$ & $-10.11(66)$ & -0.40 & -0.29 \\
$\mathbf{7}$ & -5.18 & 0.40 & -5.58 & $-4.06(26)$ & 9.74 & $-1.96(13)$ & $-9.31(61)$ & -0.34 & -0.31 \\
$\mathbf{8}$ & -5.42 & 0.34 & -5.76 & $-3.94(26)$ & 9.40 & $-2.12(14)$ & $-9.10(60)$ & -0.43 & -0.37 \\
$\mathbf{9}$ & -4.91 & 0.34 & -5.25 & $-3.59(23)$ & 10.33 & $-1.80(12)$ & $-10.18(65)$ & -0.40 & -0.27 \\
$\mathbf{1 0}$ & -4.21 & 0.35 & -4.56 & $-2.99(21)$ & 9.56 & $-1.60(11)$ & $-9.52(67)$ & -0.38 & -0.22 \\
\hline
\end{tabular}

$\Delta \mathrm{E}$ : bond energy; $\Delta \mathrm{E}_{\text {prep }}$ : preparation energy; $\Delta \mathrm{E}_{\mathrm{int}}$ : interaction energy; $\Delta \mathrm{V}_{\text {elstat }}$ : eletrostatic energy; $\Delta \mathrm{E}_{\text {Pauli }}$ : Pauli repulsion; $\Delta \mathrm{E}_{\mathrm{oi}}:$ orbital interaction energy; $\Delta \mathrm{E}_{\mathrm{disp}}$ : dispersion energy; $\Delta \mathrm{E}_{\mathrm{oi}, 1}$ and $\Delta \mathrm{E}_{\mathrm{oi}, 2}$ : energetic contribution of the first and second density deformation channel. 


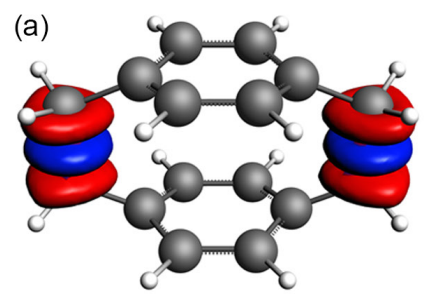

$\Delta \rho_{1}$

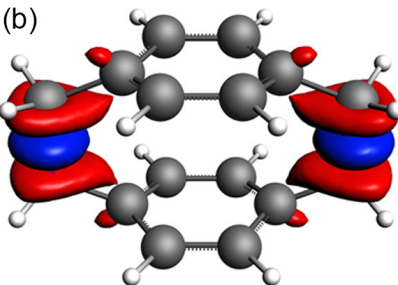

$\Delta \rho_{2}$ (c)

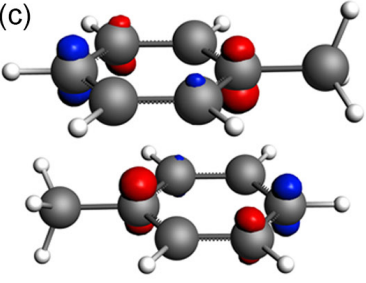

$\Delta \rho_{1}$

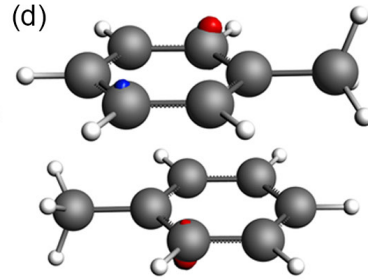

$\Delta \rho_{2}$

Figure 5. Selected density deformation channel surface plots, $\Delta \rho_{1}$ and $\Delta \rho_{2}$, for $\mathbf{1}$ (a and b) and $\mathbf{6}$ (c and d). The red and blue regions indicate the electronic density outflow and inflow, respectively. The isovalue that was used to represent these surfaces is equal to 0.004 a.u.

section) illustrate the most important density deformation channels, $\Delta \rho_{1}$ and $\Delta \rho_{2}$. The representation of the $\Delta \rho_{1}$ and $\Delta \rho_{2}$ surfaces associated with the orbital interaction energies, $\Delta \mathrm{E}_{\mathrm{oi}, 1}$ and $\Delta \mathrm{E}_{\mathrm{oi}, 2}$, (Table 4) show that the $\sigma$ bonds between the carbon atoms of the bridges in 1-5 are the most relevant interactions between the ${ }^{\circ}\left(\mathrm{CH}_{2}\right)-\mathrm{C}_{6} \mathrm{H}_{4}-\left(\mathrm{CH}_{2}\right)$ fragments. The $\Delta \rho_{1}$ and $\Delta \rho_{2}$ surfaces in 6-10 reveal longrange interactions between the carbon atoms present in the aromatic rings of the $\mathrm{CH}_{3}-\mathrm{C}_{6} \mathrm{H}_{5}$ fragments. These interactions show lower $\Delta \mathrm{E}_{\mathrm{oi}, 1}$ and $\Delta \mathrm{E}_{\mathrm{oi}, 2}$ values relative to the $\sigma$ bond interactions present in $\mathbf{1 - 5}$, which is expected since the systems are not covalently bonded.

\section{Conclusions}

We have analyzed several controversial points of the electronic structure of $[2,2]$ cyclophanes. Frontier molecular orbitals and Hirshfeld partition of electron density for the rings and the bridges indicated that the inter-ring interactions, or through space (ts), are more important than the through bond (tb) interactions. The electron density difference maps indicate that upon the formation of the toluene dimers from its monomers $\rho$ migrates inside the cavity, from the center of this region to the contiguity of the carbons. This indicates that $\rho$ is not concentrated in the external part of the ring; that is, the so called "toothpaste-tube effect" is not observed. There are lines of constant positive $\nabla^{2} \rho$ inside the cavity, suggesting that $\rho$ is depleted, or there is a valence shell charge depletion in the inter-ring region. IQA indicated that the C---C interaction between different rings are of van der Waals type, with small covalent character. The same conclusion was reached by ELF and NCI. All these analyses showed that the cyclophanes and toluene dimers behave similarly, reinforcing the small role of tb interactions. On the basis of EDA, the most important contributions in the case of toluene dimers, which only present ts interactions, are attractive dispersion and Pauli repulsion or van der Waals interaction. Except for [2,2]paracyclophane and the equivalent dimer, QTAIM molecular graphs for all the systems presented inter-ring bond paths (BPs), which are the preferential exchange-correlation paths. The stable BP indicated attractive regions in the NCI inter-ring map. The $\mathrm{NCI}$ inter-ring surface is not uniform, but presents attractive and repulsive regions.

\section{Supplementary Information}

Supplementary information (geometric parameters, HOMO and LUMO energies, distance between rings, Hirshfeld analysis, electron density difference maps, delocalization indexes and IQA components, contour maps and molecular graphs obtained from QTAIM, selected density deformation channels) is available free of charge at http://jbcs.sbq.org.br as PDF file.

\section{Acknowledgments}

This work was financially supported by the Brazilian agencies Coordenação de Aperfeiçoamento de Pessoal de Nível Superior Brazil (CAPES) finance code 001, Conselho Nacional de Desenvolvimento Científico e Tecnológico (CNPq) (grant 304447/2010-2), and São Paulo Research Foundation (FAPESP, Fundação de Amparo à Pesquisa do Estado de São Paulo) (grants 2008/02677-0, 2014/50265-3, 2017/04856-8, 2011/07623-8 and 2017/24856-2) for financial support. SEG and RLTP thank CNPq for research fellowships (grants 308254/2016-3 and 313648/2018-2, respectively). The authors acknowledge Ali Faez Taha for technical assistance, Cynthia M. C. Prado Manso for revising the manuscript, Prof Tian $\mathrm{Lu}$ and the three referees for several helpful comments.

\section{References}

1. Kovac, B.; Mohraz, M.; Heilbronner, E.; Boekelheide, V.; Hopf, H.; J. Am. Chem. Soc. 1980, 102, 4314.

2. Heilbronner, E.; Yang, Z. Z.; Top. Curr. Chem. 1983, 115, 1.

3. Galembeck, S. E.; Caramori, G. F.; Misturini, A.; Garcia, L. C.; Orenha, R. P.; Organometallics 2017, 36, 3465.

4. Dyson, P. J.; Humphrey, D. G.; McGrady, J. E.; Mingos, D. M. P.; Wilson, D. J.; J. Chem. Soc., Dalton Trans. 1995, 4039. 
5. Salcedo, R.; Sansores, L. E.; Martinez, A.; Alexandrova, L.; Garcia, M.; J. Organomet. Chem. 2000, 603, 225.

6. Quinonero, D.; Frontera, A.; Garau, C.; Ballester, P.; Costa, A.; Deya, P. M.; Pichierri, F.; Chem. Phys. Lett. 2005, 408, 59.

7. Lyssenko, K. A.; Antipin, M. Y.; Antonov, D. Y.; ChemPhysChem 2003, 4, 817.

8. Starikova, Z. A.; Fedyanin, I. V.; Antipin, M. Y.; Russ. Chem. Bull. 2004, 53, 1779.

9. Wolf, H.; Jorgensen, M. R. V.; Chen, Y.-S.; Herbst-Irmer, R.; Stalke D.; Acta Crystallogr., Sect. B: Struct. Sci., Cryst. Eng. Mater. 2015, 71, 10.

10. Misturini, A.; Ortolan, A. O.; Caramori, G. F.; Cintra, C. H.; Parreira, R. L. T.; New J. Chem. 2019, 43, 13271.

11. Hernandez-Trujillo, J.; Theor. Chem. Acc. 2016, 135, 198.

12. Caramori, G. F.; Galembeck, S. E.; J. Phys. Chem. A 2007, 111, 1705.

13. Bond, A. M.; Dyson, P. J.; Humphrey, D. G.; Lazarev, G.; Suman, P.; J. Chem. Soc., Dalton Trans. 1999, 443.

14. Bartholomew, G. P.; Bazan, G. C.; Acc. Chem. Res. 2001, 34, 30.

15. Zyss, J.; Ledoux, I.; Volkov, S.; Chernyak, V.; Mukamel, S.; Bartholomew, G. P.; Bazan, G. C.; J. Am. Chem. Soc. 2000, $122,11956$.

16. Grimme, S.; Chem. - Eur. J. 2004, 10, 3423.

17. Grimme, S.; Mueck-Lichtenfeld, C.; Isr. J. Chem. 2012, 52, 180.

18. Meitei, O. R.; Heßelmann, A.; ChemPhysChem 2016, 17, 3863.

19. Majerz, I.; Dziembowska, T.; Mol. Diversity 2020, 24, 11.

20. Alonso, M.; Woller, T.; Martin-Martinez, F. J.; Contreras-Garcia, J.; Geerlings, P.; de Proft, F.; Chem.- Eur. J. 2014, 20, 4931.

21. Watt, M.; Hardebeck, L. K. E.; Kirkpatrick, C. C.; Lewis, M.; J. Am. Chem. Soc. 2011, 133, 3854.

22. Majerz, I.; Dziembowska, T.; J. Phys. Chem. A 2016, 120, 8138.

23. Karter-Fenk, J.; Hebert, J. M.; Chem. Sci. 2020, 11, 6758.

24. Karter-Fenk, J.; Hebert, J. M.; Phys. Chem. Chem. Phys. 2020, 22, 24870.

25. Baldridge, K. K.; Battersby, T. R.; VernonClark, R.; Siegel, J. S.; J. Am. Chem. Soc. 1997, 119, 7048.

26. Caramori, G. F.; Galembeck, S. E.; Laali, K. K.; J. Org. Chem. 2005, 70, 3242.

27. Caramori, G. F.; Galembeck, S. E.; J. Phys. Chem. A 2008, 112, 11784.

28. Orenha, R. P.; Caramori, G. F.; Misturini, A.; Galembeck, S. E.; J. Mol. Model. 2019, 25, 11.

29. Lu, T.; Chen, F. W.; Acta Chim. Sinica 2011, 69, 2393.

30. Bader, R. F. W.; Atoms in Molecules: A Quantum Theory; Cleredon Press: Oxford, 1994.

31. Blanco, M. A.; Pendas, A. M.; Francisco, E.; J. Chem. Theory Comput. 2005, 1, 1096.

32. Silvi, B.; Savin, A.; Nature 1994, 371, 683.

33. Johnson, E. R.; Keinan, S.; Mori-Sanchez, P.; Contreras-Garcia,
J.; Cohen, A. J.; Yang, W. T.; J. Am. Chem. Soc. 2010, 132, 6498.

34. Bickelhaupt, F. M.; Baerends, E. J. In Reviews in Computational Chemistry, vol. 15; Lipkowitz, K. B.; Boyd, D. B., eds.; WileyVCH: New York, USA, 2000, p. 1.

35. Mitoraj, M.; Michalak, A.; J. Mol. Model. 2007, 13, 347; Mitoraj, M. P.; Michalak, A.; Ziegler, T.; J. Chem. Theory Comput. 2009, 5, 962.

36. Zhao, Y.; Truhlar, D. G.; J. Phys. Chem. A 2005, 109, 5656.

37. Grimme, S.; Ehrlich, S.; Goerigk, L.; J. Comput. Chem. 2011, $32,1456$.

38. Weigend, F.; Ahlrichs, R.; Phys. Chem. Chem. Phys. 2005, 7, 3297; Weigend, F.; Phys. Chem. Chem. Phys. 2006, 8, 1057.

39. Neese, F.; Wiley Interdiscip. Rev.: Comput. Mol. Sci. 2012, 2 , 73.

40. AIMAll, version 19.02.13; T. A. Keith, T. K. Gristmill Software, Overland Park KS, USA, 2016, available at aim.tkgristmill.com, accessed in March 2021.

41. Lu, T.; Chen, F. W.; J. Comput. Chem. 2012, 33, 580.

42. Becke, A. D.; J. Chem. Phys. 1988, 38, 3098; Lee, C.; Hill, C.; Carolina, N.; Chem. Phys. Lett. 1989, 162, 165.

43. van Lenthe, E.; Baerends, E. J.; J. Comput. Chem. 2003, 24, 1142.

44. te Velde, G.; Bickelhaupt, F. M.; Baerends, E. J.; Fonseca Guerra, C.; van Gisbergen, S. J. A.; Snijders, J. G.; Ziegler, T.; J. Comput. Chem. 2001, 22, 931; Fonseca Guerra, C.; Snijders, J. G.; te Velde, G.; Baerends, E. J.; Theor. Chem. Acc. 1998, 99 , 391.

45. Wolf, H.; Leusser, D.; Jorgensen, M. R. V.; Herbst-Irmer, R.; Chen, Y.-S.; Scheidt, E.-W.; Scherer, W.; Iversen, B. B.; Stalke, D.; Chem. - Eur. J. 2014, 20, 7048.

46. Wolf, H.; Lock, N.; Parker, S. F.; Stalke, D.; Chem. - Eur. J. 2015, 21, 4556.

47. Bachrach, S. M.; J. Phys. Chem. A 2011, 115, 2396.

48. Renault, A.; Cohen-Addad, C.; Lajzerowicz-Bonneteau, J.; Dutasta, J.-P.; Crisp, M. J.; Acta Crystallogr., Sect. B: Struct. Sci., Cryst. Eng. Mater. 1987, 43, 480.

49. Sinnokrot, M. O.; Sherrill, C. D.; J. Phys. Chem. A 2004, 108, 10200.

50. Pendas, A. M.; Francisco, E.; Blanco, M. A.; Gatti, C.; Chem. - Eur. J. 2007, 13, 9362.

51. Grabowski, S. J.; Chem. Rev. 2011, 111, 2597.

52. Ziolkowski, M.; Grabowski, S. J.; Leszczynski, J.; J. Phys. Chem. A 2006, 110, 6514.

53. Grin, Y.; Savin, A.; Silvi, B. In The ELF Perspective of Chemical Bonding (The Chemical Bond: Fundamental Aspects of Chemical Bonding), 1 ${ }^{\text {st }}$ ed.; Frenking, G.; Shaik, S., eds.; Wiley-VCH: Weinheim, Germany, 2014, p. 345.

Submitted: November 19, 2020 Published online: April 5, 2021 